\title{
Risk factors for refractory septic shock treated with VA ECMO
}

\author{
Lei Han ${ }^{1}$, Yan Zhang ${ }^{2}$, Yonghui Zhang ${ }^{2}$, Wei Wu ${ }^{3}$, Ping $\mathrm{He}^{4}$ \\ ${ }^{1}$ Medical and Education Department, ${ }^{2}$ Critical Care Medicine, ${ }^{3}$ Thoracic Surgery Department, ${ }^{4}$ Cardiac Surgery Department, Southwest Hospital, \\ the First Hospital Affiliated to Army Medical University, Chongqing 400038, China \\ Contributions: (I) Conception and design: L Han, P He, W Wu; (II) Administrative support: W Wu, P He ; (III) Provision of study materials or \\ patients: Y Zhang, Y Zhang, P He; (IV) Collection and assembly of data: L Han, Y Zhang, Y Zhang; (V) Data analysis and interpretation: L Han, W \\ Wu, P He ; (VI) Manuscript writing: All authors; (VII) Final approval of manuscript: All authors. \\ Correspondence to: Wei Wu. Thoracic Surgery Department, Southwest Hospital, the First Hospital Affiliated to Army Medical University, Chongqing \\ 400038, China. Email: wuweiyahoo@sohu.com; Ping He. Cardiac Surgery Department, Southwest Hospital, the First Hospital Affiliated to Army \\ Medical University, Chongqing 400038, China. Email: yhp0130@sina.com.
}

\begin{abstract}
Background: Refractory septic shock is a serious disorder with high mortality. There is currently limited evidence to support the use of extracorporeal membrane oxygenation (ECMO) in adult septic shock. We describe the outcome of patients with refractory septic shock in our hospital and try to identify prognostic factors.

Methods: We studied a total of 23 (14 males and 9 females) refractory septic shock patients treated with venoarterial (VA) ECMO in our hospital. Clinical parameters of survival and death groups, laboratory parameters before and after ECMO placement were analyzed.

Results: Eight patients were successfully weaned off ECMO and five patients were discharged. The sepsisrelated organ failure assessment (SOFA) score and shock-to-ECMO interval before ECMO placement in the survival group were significantly lower than those in the death group (12.0 vs. 15.0, $\mathrm{P}=0.007 ; 23.5$ vs. $42.2 \mathrm{~h}$, $\mathrm{P}=0.037)$. The number of cases who had the normal range of $\mathrm{ScvO}_{2} \%$ between the survival group and the death group at $12 \mathrm{~h} \mathrm{(4} \mathrm{vs.} \mathrm{4,} \mathrm{P}=0.033), 18 \mathrm{~h} \mathrm{(5} \mathrm{vs.} \mathrm{7,} \mathrm{P}=0.016)$ and $24 \mathrm{~h}$ (5 vs. 9, $\mathrm{P}=0.043)$ during ECMO was significantly different. In univariate logistic regression analysis, the case of patients with normal central venous oxygen saturation $\left(\mathrm{ScvO}_{2}\right) \%$ at $12 \mathrm{~h}$ during ECMO [odds ratio (OR) 14.0, 95\% confidence interval (CI): 1.200-163.367, $\mathrm{P}=0.035$ ] was significantly associated with risk of the prognosis of patients.
\end{abstract}

Conclusions: In adult refractory septic shock patients, $\mathrm{ScvO}_{2} \%$ at $12 \mathrm{~h}$ during ECMO may be a risk factor for patient prognosis.

Keywords: Extracorporeal membrane oxygenation (ECMO); refractory septic shock; risk factors

Submitted May 02, 2019. Accepted for publication Jul 24, 2019.

doi: 10.21037/atm.2019.08.07

View this article at: http://dx.doi.org/10.21037/atm.2019.08.07

\section{Introduction}

Sepsis is defined as a life-threatening organ dysfunction due to dysregulated response to infection. Septic shock is defined as a branch of sepsis in which potential circulation and cellular metabolism are severely abnormal so that the mortality is significantly increased (1). Severe sepsis or septic shock is one of the major causes of pediatric death. It accounted for about $8 \%$ pediatric intensive care unit (PICU) admission and the proportion varied across regions from $6.2 \%$ to $23.1 \%$ (1). The overall mortality rate was $24 \%$, ranging from $21 \%$ in North America and $40 \%$ in Africa. After 1990, strict anticoagulation management and improvements in extracorporeal membrane oxygenation (ECMO) management have reduced ECMO-related complications $(2,3)$. In successively published guidelines $(4,5)$, ECMO can be considered for septic shock patients who do not respond to fluid resuscitation and positive inotropic drugs. However, the role of venoarterial (VA) ECMO in adult septic shock remains controversial, and the 


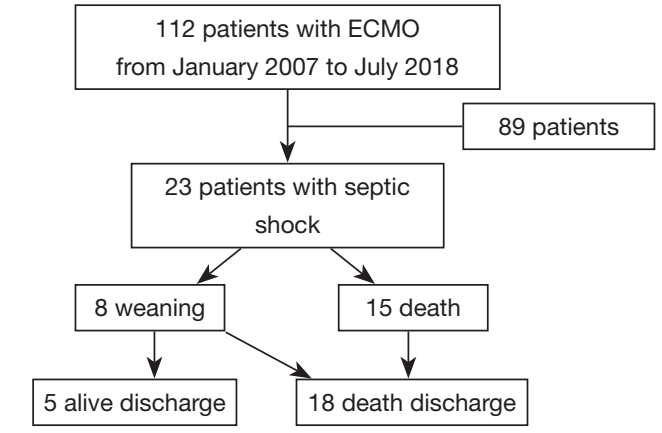

Figure 1 Patient flow chart.

analysis of prognostic factors in these patients is limited with clinical outcomes being inconsistent. Some studies (6) reported $85 \%$ of hospital mortality, while others reported $29 \%$ of hospital mortality (4/14) (7-9). Therefore, we sought to investigate the clinical outcomes of adult patients supported by VA ECMO during refractory septic shock from an ECMO registry at our ECMO center.

\section{Methods}

\section{Patients}

We conducted a retrospective study of patients with refractory septic shock (10) who received ECMO from January 2007 to December 2017. The total number of VA ECMO patients during the observation time was 112, among which 23 (20.54\%) patients received ECMO for refractory septic shock and they were selected for the main study cohort. A total of 23 patients, 14 males (60.87\%), 9 females (39.13\%), had a median age of 53 years. All patients were treated with continuous renal replacement therapy (CRRT), and 2 of them received plasma exchange (Figure 1).

\section{ECMO indications}

Inclusion criteria were patients with persistent circulatory failure or worsened refractory septic shock despite treatment with fluids resuscitation, adequate antibiotics and vasoactive drugs. Specific indications: organ hypoperfusion (extensive skin mottling, progressive lactic acidosis, oliguria or altered mental status), despite adequate intravascular volume and the inability to maintain mean arterial pressure $>65 \mathrm{mmHg}$, despite infusion of very high-dose catecholamines (norepinephrine $>1 \mu \mathrm{g} / \mathrm{kg} / \mathrm{min}$, dopamine $>20 \mu \mathrm{g} / \mathrm{kg} / \mathrm{min}$ or epinephrine
$>1 \mu \mathrm{g} / \mathrm{kg} / \mathrm{min}$ with dobutamine $>20 \mu \mathrm{g} / \mathrm{kg} / \mathrm{min}$ ) (10). There is no standard vasopressin in China, so we have little experience in this area. We only use dopamine occasionally.

Exclusion criteria were patients with an advanced malignant tumor, cardiopulmonary resuscitation (CPR) $>60 \mathrm{~min}$, irreversible neuropathy, such as a large number of intracranial hemorrhage.

\section{ECMO implantation and management}

ECMO catheterization was operated by an experienced ECMO team and was often carried out at the bedside. All patients underwent peripheral cannulation: the arterial catheter was placed into the femoral artery, and the venous catheter was placed into the femoral vein or internal jugular vein. Femoral artery cannula size was 17-19 Fr, femoral vein cannula size was 19-21 Fr. After the arterial cannulation, the distal branch was inserted to perform lower limb perfusion.

The ECMO centrifugal pump and membrane lung were from Maquet (Fairfield, NJ, USA). The intubation was performed using a surgical incision catheter. Because the patient's hemodynamics were often unstable, all catheters were placed by a trained cardiovascular surgeon at the bedside. The initial flow rate was $4-6 \mathrm{~L} / \mathrm{min}$ of blood flow, maintaining the ACT at 160-220 sec. Vasoactive drugs were properly used to maintain an average arterial pressure of $60-70 \mathrm{mmHg}$, a hematocrit of $30-35 \%$, and a platelet count of $\geq 50,000 / \mathrm{mm}^{3}$. Echocardiography was performed daily to monitor cardiac function. The ECMO weaning test was gradually performed according to the patient's systemic hemodynamics and tissue perfusion improvement. Successful weaning was defined as maintaining stable condition within 24 hours of ECMO weaning.

\section{Data collection}

The primary data of this study was survival rate after discharge. The following detailed data were obtained through a medical review at 24 hours prior to ECMO implantation: age, body mass index (BMI), mechanical assistant time [ECMO, CRRT, mechanical ventilation (MV)], ICU length of stay, hospital length of stay. The clinical biochemical indexes were assessed, including blood routine examination, arterial blood gas analysis, liver function, renal function, coagulation function, shock-toECMO interval and the severity of the disease of the sepsisrelated organ failure assessment (SOFA) score. 


\section{Statistical analysis}

All analyses were performed with commercially available statistical software (SPSS v22.0). Patients were categorized into two groups, survivors and non-survivors. The values are presented as the mean \pm standard deviation $(\mathrm{SD})$. Laboratory findings were compared between the two groups using the Student's $t$-test for normally distributed variables or the Mann-Whitney U-test for continuous data. The proportions of patients were compared using Fisher's exact test. Univariate logistic regressions were applied to perform analysis for predicting the most significant factors associated with mortality. $\mathrm{P}<0.05$ was considered statistically significant.

\section{Results}

\section{Baseline characteristics}

Between January 2007 and December 2017, 112 patients underwent VA ECMO due to cardiogenic shock. There were 23 patients with septic shock after 89 patients were excluded according to the exclusion criteria. Fifteen patients (65.22\%) were unable to withdraw from ECMO; 8 patients (34.78\%) had successful weaning of ECMO, and 3 patients died after weaning because of primary infection (2 patients with extensive burns). Five patients with successful weaning survived until discharge (Figure 1).

Although the BMI, ECMO time, CRRT time, mechanical ventilation time, and ICU time in the death group were longer than those in the survival group, and the hospital stay was shorter than the survival group, the difference was not statistically significant. The SOFA score and shock-to-ECMO interval before ECMO placement in the survival group were significantly lower than those in the death group (12.0 vs. 15.0, $\mathrm{P}=0.007 ; 23.5$ vs. $42.2 \mathrm{~h}$, $\mathrm{P}=0.037)$.

There was significant difference in the number of cases who had the normal range of central venous oxygen saturation $\left(\mathrm{ScvO}_{2}\right) \%$ between the survival group and the death group at $12 \mathrm{~h}(4$ vs. $4, \mathrm{P}=0.033), 18 \mathrm{~h}$ ( 5 vs. 7 , $\mathrm{P}=0.016)$ and $24 \mathrm{~h}(5$ vs. 9, $\mathrm{P}=0.043)$ during ECMO (Table 1, Figure 2).

\section{Causal pathogens}

Of the 23 patients, 11 (47.83\%) patients had infection, 9 of which were bacteremia, 1 was viral infection, and 1 was fungal infection. Of the 9 bacterial infections, 3 (13.1\%) had Staphylococcus epidermidis in the blood, 2 (8.7\%) had Enterococcus in ascites, and $2(8.7 \%)$ had Stapbylococcus aureus in skin secretion, 2 patients had Escherichia coli and Acinetobacter baumannii in urinary tract and lung, respectively. In addition, 1 patient had intestinal infection with Coxsackie and 1 patient had skin infection of Candida albicans (Table 2).

\section{Clinical outcomes of VA ECMO in refractory septic shock}

In the univariate analysis, there was no significant difference in age, BMI, ECMO duration, CRRT duration, Mechanical ventilation, ICU length of stay, hospital length of stay, SOFA, various biochemical parameters and shock-toECMO interval between the survival group and death group (Table 3).

\section{$\mathrm{ScvO}_{2} \%$ at $24 \mathrm{~b}$ during ECMO between survival and death group}

The changes of $\mathrm{ScvO}_{2} \%$ in the two groups were observed dynamically within $24 \mathrm{~h}$ (Figure 3). Univariate logistic regression analysis revealed that the case of patients with normal $\mathrm{ScvO}_{2} \%$ at $12 \mathrm{~h}$ during ECMO was the risk factors for the prognosis of patients [odds ratio (OR) 14.0, 95\% confidence interval (CI): 1.200-163.367, $\mathrm{P}=0.035$ ] (Table 4).

\section{Discussion}

Sepsis is the most common cause of death in the ICU with a mortality rate of more than $40 \%$ (11). If sepsis progresses to refractory septic shock, even if it is actively treated with conventional treatment, its mortality rate is still as high as $90-100 \%$ (12). Refractory septic shock can occur during ECMO bypass. It usually occurs in patients with long bypass time, such as those waiting for cardiopulmonary transplantation (13), and in patients with severe infection risk of primary diseases, such as large area burns (14) and infectious endocarditis (15), which have a high mortality rate. The shock-to-ECMO interval refers to the interval between the start of the use of vasoactive drugs and the initiation of ECMO. Whether the length of shock-to-ECMO interval is related to the prognosis of patients is not clear. Taek et al. treated 32 refractory septic shock patients with VA ECMO (survival rate $21.9 \%$ ). The shock-to-ECMO interval was 21.1 $\mathrm{h}$ in 7 patients in the survival group and $24.9 \mathrm{~h}$ in 25 patients in the death group. There was no significant 
Table 1 Comparison of clinical data between survival and death groups

\begin{tabular}{|c|c|c|c|}
\hline Factors & Survival group $(n=5)$ & Death group $(n=18)$ & $P$ value \\
\hline BMI & 20.9 (19.3-22.9) & $22.6(20.3-23.7)$ & 0.297 \\
\hline ECMO duration (h) & $146.0(125.5-167.5)$ & $159.0(142.5-205.3)$ & 0.331 \\
\hline CRRT duration (h) & $134.0(80.5-144.5)$ & 125.0 (111.3-206.5) & 0.412 \\
\hline ICU length (days) & $12.0(8.5-17.5)$ & $16.5(13.0-19.3)$ & 0.124 \\
\hline Hospital length (days) & $19.0(17.5-21.0)$ & $16.5(13.0-21.0)$ & 0.312 \\
\hline \multicolumn{4}{|l|}{$\mathrm{ScvO}_{2} \%$ at $24 \mathrm{~h}$ during $\mathrm{ECMO}$} \\
\hline ECMO initiation & $1(20.00 \%)$ & $2(11.11 \%)$ & 0.602 \\
\hline $18 \mathrm{~h}$ during $\mathrm{ECMO}$ & $5(100.00 \%)$ & $7(38.89 \%)$ & $0.016^{*}$ \\
\hline $24 \mathrm{~h}$ during ECMO & $5(100.00 \%)$ & $9(50.00 \%)$ & $0.043^{*}$ \\
\hline Shock-to-ECMO interval (h) & 23.5 (14.7-26.9) & $42.2(24.3-80.9)$ & $0.037^{\star}$ \\
\hline WBC & $12.9(9.8-16.5)$ & $12.2(10.4-14.0)$ & 0.801 \\
\hline $\mathrm{pH}$ & $7.14(6.96-7.32)$ & $7.17(7.03-7.28)$ & 0.971 \\
\hline Lac & $4.4(2.2-7.4)$ & $6.8(5.5-8.9)$ & 0.067 \\
\hline SOFA & $12.0(10.0-13.0)$ & $15.0(13.0-18.3)$ & $0.007^{*}$ \\
\hline ALT & $123.0(88.0-184.0)$ & $105.5(88.5-124.8)$ & 0.446 \\
\hline APTा & $53.0(46.5-60.0)$ & 55.5 (49.3-64.3) & 0.446 \\
\hline
\end{tabular}

Values are median (25th to 75th percentile). ${ }^{*}, \mathrm{P}<0.05 . \mathrm{BMI}$, body mass index; ECMO, extracorporeal membrane oxygenation; CRRT, continuous renal replacement therapy; MV, mechanical ventilation; ICU, intensive care unit; $\mathrm{ScvO}_{2}$, central venous oxygen saturation; WBC, white blood cell; SOFA, sepsis-related organ failure assessment; ALT, alanine aminotransferase; TBIL, total bilirubin; Cr, creatinine; $\mathrm{PCT}$, procalcitonin; $\mathrm{Hb}$, hemoglobin; PT, prothrombin time; APTT, activated partial thromboplastin time.

difference between the two groups $(\mathrm{P}=0.45)$. However, none of the patients with $>30.5 \mathrm{~h}$ shock-to-ECMO interval survived (8). Choi et al. performed a retrospective analysis of 28 patients with septic shock [21 in VA, 4 in venovenous (VV), 3 in venoarterial-venous] (mortality $35.7 \%$ ). The shock-to-ECMO interval was $3.3 \mathrm{~h}$ in 10 patients in the survival group and $6.4 \mathrm{~h}$ in 18 patients in the death group. There was no significant difference between the two groups $(\mathrm{P}=0.436)$ (16). Ro et al. performed a retrospective analysis of 71 septic shock patients treated with ECMO (survival rate was only $7 \%$ ). The shock-to-ECMO interval was $4 \mathrm{~h}$ in 5 patients in the survival group and $18 \mathrm{~h}$ in 66 patients in the death group. There was no significant difference between the two groups $(\mathrm{P}=0.052)$ (17). Our results showed that the shock-to-ECMO interval was $5 \mathrm{~h}$ in 5 patients in the survival group and $18 \mathrm{~h}$ in 18 
patients in the death group. There was a statistically significant difference between the two groups $(\mathrm{P}=0.037)$, but the univariate analysis showed that the shock-to-ECMO interval was not associated with patient discharge survival $(\mathrm{P}=0.136)$.

Choi et al. analyzed 28 septic shock patients (35.7\% discharge rate) treated with VA, VV, and VAV ECMO. Although univariate analysis showed that SOFA score was associated with patient discharge survival, this correlation was not found in multivariate analysis (16). Chang et al. found that among 55 children with sepsis who received ECMO support (31\% discharge survival rate), there was a significant difference in SOFA between the survival and death group within 7 days of ECMO treatment $(\mathrm{P}<0.05)$, but there was no significant difference in SOFA after 1 week of ECMO support (18). Ro et al. found that, among 71 septic shock patients treated with VA ECMO (7\% discharge survival rate), although the average SOFA score was slightly

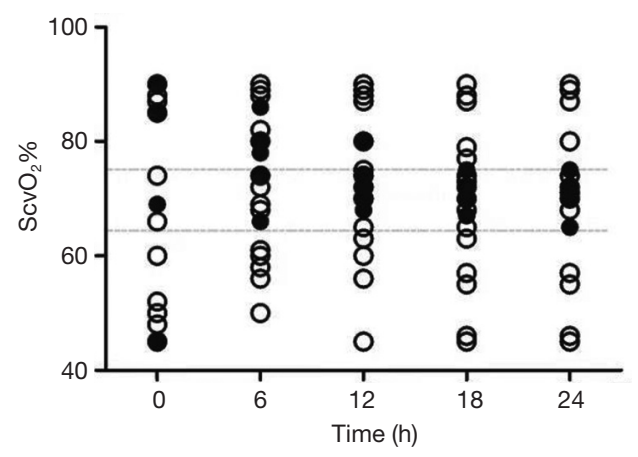

Figure 2 Comparison of $\mathrm{ScvO}_{2} \%$ in $24 \mathrm{~h}$ during ECMO between survivors (solid polt) and non-survivors (hollow polt). $\mathrm{ScvO}_{2}$, central venous oxygen saturation; ECMO, extracorporeal membrane oxygenation. lower in the survival group than that in the death group, the difference was not statistically significant (17). Ferreira et al. found that, among 32 patients with refractory septic shock (21 males) who received ECMO support therapy, 7 patients $(21.9 \%)$ survived until discharge. When ECMO was initiated, the simplified acute physiology score (SAPS) 3 and SOFA scores of the two groups of patients were similar. However, the third day SOFA score (15 vs. 18, $\mathrm{P}=0.01)$ and subsequent SOFA score ( 1 vs. $4, \mathrm{P}=0.04)$ were significantly different between the survival and death groups. The trend of SOFA score over time can reflect the patient's response to ECMO support and objectively evaluate the response to treatment (19). This change can facilitate decision-making regarding the appropriateness of organ support (8). In our group of patients, the SOFA score (12.0) in the survival group were statistically lower than that in the death groups (15.0, $\mathrm{P}=0.007)$. The univariate analysis showed that the $\mathrm{P}$ value was close to 0.05 ( $\mathrm{P}=0.051)$, which maybe need to further expand the sample size to clarify.

Systemic hypoxia is a common and important complication of sepsis and may lead to multiple organ dysfunction syndrome. $\mathrm{ScvO}_{2} \%$ (oxygen saturation in superior vena cava) indicates the level of venous oxygenation in the brain and upper body, with normal values between $73 \%$ and $82 \%$. An important feature of venous oxygen saturation is that when it is too high or too low, it represents a pathological state. In a recent cohort of large sepsis patients in the emergency department, it was found that patients with $\mathrm{ScvO}_{2} \%<70 \%$ had a mortality rate of $40 \%$, while patients with $\mathrm{ScvO}_{2} \%>90 \%$ also had a mortality rate as high as $34 \%(20)$. Patients with a high initial $\mathrm{ScvO}_{2} \%$ value may also lead to adverse outcomes (21), which may be due to microcirculatory failure, resulting in reduced oxygen uptake by the tissue. Park et al. studied 169 patients

Table 2 Infection characteristics of the 23 septic shock patients with VA ECMO

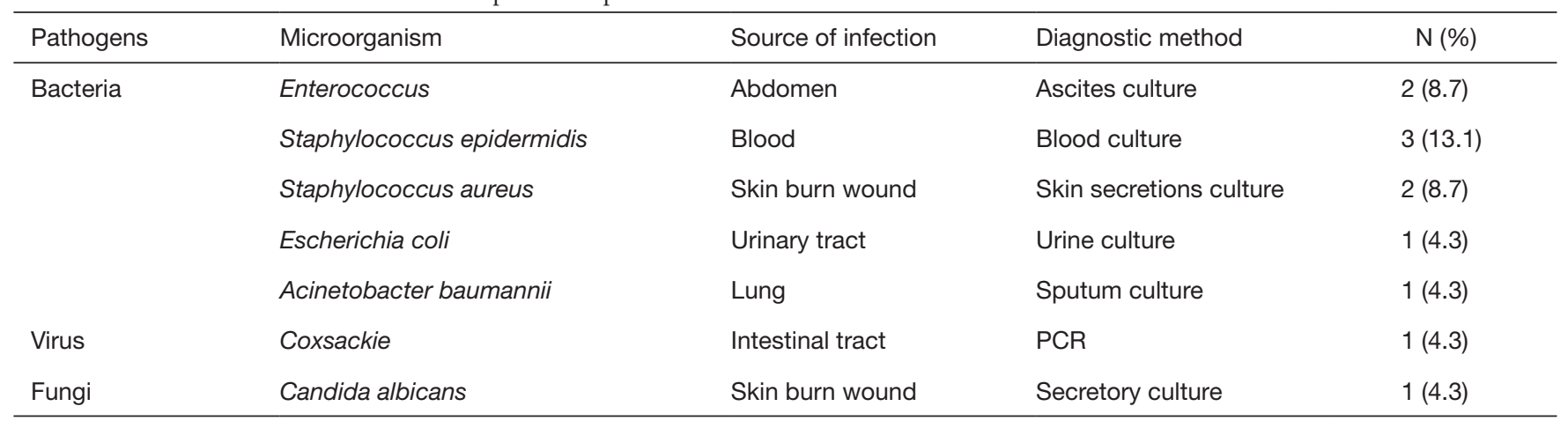

VA ECMO, venoarterial extracorporeal membrane oxygenation; PCR, polymerase chain reaction. 
Table 3 Univariate analysis of risk factors of clinical data between survival and death groups

\begin{tabular}{|c|c|c|c|c|c|}
\hline Factors & Survival group $(n=5)$ & Death group $(n=18)$ & Walds & $P$ value & OR $(95 \% \mathrm{Cl})$ \\
\hline BMI & 20.9 (19.3-22.9) & $22.6(20.3-23.7)$ & 1.119 & 0.290 & $1.303(0.798-2.128)$ \\
\hline ECMO duration (h) & $146.0(125.5-167.5)$ & $159.0(142.5-205.3)$ & 1.033 & 0.310 & $1.014(0.988-1.040)$ \\
\hline CRRT duration (h) & $134.0(80.5-144.5)$ & $125.0(111.3-206.5)$ & 1.516 & 0.218 & $1.019(0.989-1.051)$ \\
\hline ICU length (days) & $12.0(8.5-17.5)$ & $16.5(13.0-19.3)$ & 2.835 & 0.092 & $1.331(0.954-1.856)$ \\
\hline hospital length (days) & $19.0(17.5-21)$ & $16.5(13.0-21.0)$ & 0.931 & 0.335 & $0.876(0.670-1.146)$ \\
\hline WBC & $12.9(9.8-16.5)$ & $12.2(10.4-14.0)$ & 0.133 & 0.715 & $0.939(0.669-1.318)$ \\
\hline $\mathrm{pH}$ & 7.14 (6.96-7.32) & $7.17(7.03-7.28)$ & 0.000 & 0.995 & $1.021(0.001-873.333)$ \\
\hline ALT & $123.0(88.0-184.0)$ & $105.5(88.5-124.8)$ & 0.511 & 0.475 & $0.993(0.973-1.013)$ \\
\hline TBIL & 33.6 (29.5-42.0) & $35.5(30.8-41.3)$ & 0.081 & 0.776 & $1.023(0.873-1.200)$ \\
\hline $\mathrm{Cr}$ & $178.0(102.5-223.5)$ & $173.0(117.5-236.8)$ & 0.104 & 0.747 & $1.003(0.986-1.019)$ \\
\hline PCT & $12.7(12.5-15.6)$ & $16.1(14.4-17.4)$ & 1.551 & 0.213 & $1.284(0.866-1.903)$ \\
\hline $\mathrm{Hb}$ & $98.0(90.5-116.5)$ & $100.5(85.8-105.3)$ & 0.630 & 0.427 & $0.966(0.888-1.052)$ \\
\hline PT & $21.0(16.5-27.5)$ & 21.5 (18.8-27.3) & 0.076 & 0.782 & $1.029(0.841-1.259)$ \\
\hline APTT & $53.0(46.5-60.0)$ & 55.5 (49.3-64.3) & 0.467 & 0.494 & $1.044(0.923-1.181)$ \\
\hline Shock-to-ECMO interval (h) & 23.5 (14.7-26.9) & $42.2(24.3-80.9)$ & 2.218 & 0.136 & $1.143(0.959-1.363)$ \\
\hline
\end{tabular}

Values are median (25th to 75th percentile). OR, odd ratio; Cl, confidence interval; BMI, body mass index; ECMO, extracorporeal membrane oxygenation; CRRT, continuous renal replacement therapy; MV, mechanical ventilation; ICU, intensive care unit; ScvO ${ }_{2}$, central venous oxygen saturation; WBC, white blood cell; SOFA, sepsis-related organ failure assessment; ALT, alanine aminotransferase; TBIL, total bilirubin; $\mathrm{Cr}$, creatinine; PCT, procalcitonin; Hb, hemoglobin; PT, prothrombin time; APTT, activated partial thromboplastin time.

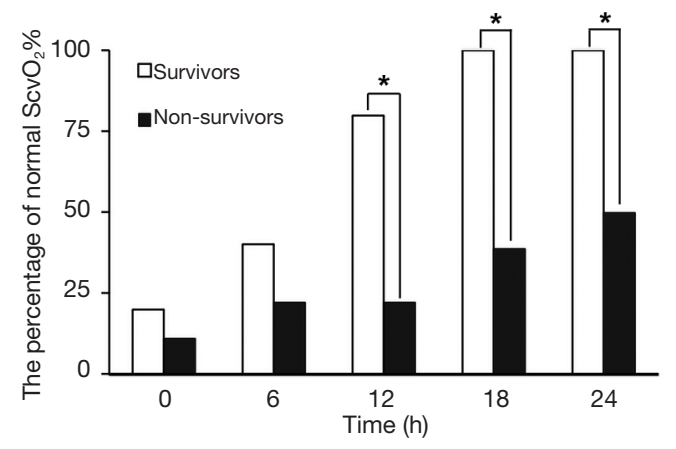

Figure 3 The percentage of patients with normal $\mathrm{ScrO}_{2} \%$ between survivors and non-survivors at $24 \mathrm{~h}$ during ECMO. $\mathrm{ScvO}_{2}$, central venous oxygen saturation; ECMO, extracorporeal membrane oxygenation. *, $\mathrm{P}<0.05$. with severe sepsis or septic shock in emergency department, and calculated their oxygen extraction rate (OER) [OER $=\mathrm{ScvO}_{2} \%$ /arterial oxygen saturation]. The results showed that the initial low OER $(<0.2)$ was associated with severe organ dysfunction and can result in a high mortality rate in patients with severe sepsis and septic shock. When the patient's initial $\mathrm{ScvO}_{2} \%$ was $>70 \%$, but had abnormally low OER, the hospitalization mortality was higher than those with normal OER (0.2-0.3), suggesting that OER should be considered when $\mathrm{ScvO}_{2} \%$ was used to predict the prognosis of patients with sepsis (22). Lee et al. (23) analyzed 363 patients with sepsis and found that $\mathrm{ScrO}_{2} \%$ at 6 hours after shock resuscitation was a prognostic factor for severe sepsis or septic shock. Shin et al. (24) analyzed 880 patients with 
Table 4 Univariate analysis of risk factors of $\mathrm{ScvO}_{2} \%$ at $24 \mathrm{~h}$ during ECMO between survival and death group

\begin{tabular}{|c|c|c|c|c|c|}
\hline Time & \multicolumn{2}{|c|}{ Case of patients with normal $\mathrm{ScvO}_{2} \%$} & Walds & $P$ value & OR $(95 \% \mathrm{Cl})$ \\
\hline ECMO initiation & $1(20 \%)$ & $2(11.11 \%)$ & 0.265 & 0.607 & $2.000(0.143-27.990)$ \\
\hline $6 \mathrm{~h}$ during $\mathrm{ECMO}$ & $2(40 \%)$ & $4(22.22 \%)$ & 0.622 & 0.430 & $2.333(0.284-19.172)$ \\
\hline $12 \mathrm{~h}$ during ECMO & $4(80 \%)$ & $4(22.22 \%)$ & 4.432 & $0.035^{\star}$ & $14.000(1.200-163.367)$ \\
\hline 24 h during ECMO & $5(100 \%)$ & $9(50.00 \%)$ & - & 0.999 & - \\
\hline
\end{tabular}

*, $\mathrm{P}<0.05 . \mathrm{ScvO}_{2}$, central venous oxygen saturation; $\mathrm{ECMO}$, extracorporeal membrane oxygenation; OR, odd ratio; $\mathrm{Cl}$, confidence interval.

septic shock or severe sepsis, and divided these patients into 4 groups: group 1 (high $\mathrm{ScvO}_{2} \%$; low lactate), group 2 (low $\mathrm{ScvO}_{2} \%$; low lactate), group 3 (high $\mathrm{ScvO}_{2} \%$; high lactate) and group 4 (low $\mathrm{ScvO}_{2} \%$; high lactate). The results showed that initial $\mathrm{ScvO}_{2} \%$ and lactate levels were significantly associated with 28-day mortality. Patients with $\mathrm{ScvO}_{2} \%$ $\geq 70 \%$ /low lactate level had the highest 28 -day survival rate. In a prospective, multicenter study, Boulain et al. found that, in 111 patients (total 363 patients) with the initial value of $\mathrm{ScvO}_{2} \%$ being less than $70 \%, \mathrm{ScrO}_{2} \%<70 \%$ in the $1^{\text {st }}$ and $6^{\text {th }}$ hour of ICU admission is associated with 28-day mortality (25).

ECMO patients often die during the procedure because the tissues and organs are not fully perfused. The circulation condition during ECMO can be determined by the flow provided by the ECMO, but the perfusion of the microcirculation is difficult to determine. Yeh et al. recorded sublingual microcirculation images using an incident dark field microscope at 12, 24, 48, 72, and 96 hours after VA ECMO placement. If the patient could be weaned of VA ECMO, the sublingual microcirculation image was recorded before and after VA ECMO removal. The authors found that there was no significant difference in heart rate, mean arterial pressure, positive inotropic drug score, and lactate level between the death group and the survival group at 12 hours after ECMO. However, the perfusion small vessel density (PSVD) and proportion of perfused vessels (PPV) ratio in the death group was significantly lower than those in the survival group, suggesting that patients with stable large circulation may have microcirculation disturbances at this time. The authors therefore believed that MAP may be less suitable to assess if patients with cardiogenic shock should receive VA ECMO-assisted circulation. In contrast, microcirculatory indicators can better reflect the perfusion of tissues and organs, and can better predict the prognosis of patients (26). In our group of patients, the survival group's $\mathrm{ScvO}_{2} \%$ reached normal level within 18 hours after ECMO, while only $50 \%$ of the patients in the death group reached normal value of $\mathrm{ScvO}_{2} \%$ at 24 hours after ECMO. After 12 hours of $\mathrm{ECMO}$, there was 1 case with $\mathrm{ScvO}_{2} \%>75 \%$ and 4 cases with normal $\mathrm{ScvO}_{2} \%$ in the survival group. In contrast, in the death group, 6 cases had $\mathrm{ScvO}_{2} \%>75 \%$ (3 cases had successful withdraw of ECMO) and 7 cases had $\mathrm{ScvO}_{2} \%$ $<65 \%$ ( 1 cases had successful withdraw of ECMO). In the univariate analysis, we have found that the case of patients with normal $\mathrm{ScrO}_{2} \%$ at $12 \mathrm{~h}$ during ECMO was the risk factors to the prognosis of patients.

However, there are some limitations to this study. We have included all patients who meet the inclusion and exclusion criteria during the study period for analysis. However, the small patient population and the retrospective of the study do not allow us to draw any conclusion about the effectiveness of septic shock VA ECMO treatment. To overcome this limitation, larger series from multi-center RCT experiments are needed to be done.

In summary, our results suggest that SOFA score before ECMO placement, shock-to-ECMO interval and the number of cases who had the normal range of $\mathrm{ScvO}_{2} \%$ at 12, 18 and 24 h during ECMO between the survival group and the death group were significantly different. Further univariate logistic regression analysis showed that $\mathrm{ScrO}_{2} \%$ at $12 \mathrm{~h}$ during ECMO may be risk factor for patient prognosis. Making $\mathrm{ScvO}_{2} \%$ of patients reach the normal range within 12 hours as far as possible may be helpful to improve the prognosis of patients.

\section{Acknowledgments}

Funding: This study was supported by the Hospital 
foundation (SWH2017ZDCX2002, SWH2016ZDCX2007, SWH2016JSTSYB-51 and SWH2017ZDCX-4202).

\section{Footnote}

Conflicts of Interest: The authors have no conflicts of interest to declare.

Ethical Statement: The authors are responsible for all aspects of the work in ensuring that questions related to the accuracy or integrity of any part of the work are appropriately investigated and resolved. The study was approved by the Ethical Committee of Southwest Hospital (the number/ID of the approval is KY 201847).

\section{References}

1. Shankar-Hari M, Phillips GS, Levy ML, et al. Developing a new definition and assessing new clinical criteria for septic shock: for the third international consensus definitions for sepsis and septic shock (sepsis-3). JAMA 2016;315:775-87.

2. Martucci G, Panarello G, Occhipinti G, et al. Anticoagulation and transfusions management in venovenous extracorporeal membrane oxygenation for acute respiratory distress syndrome: assessment of factors associated with transfusion requirements and mortality. J Intensive Care Med 2019;34:630-9.

3. Martucci G, Panarello G, Occhipinti G, et al. Impact of cannula design on packed red blood cell transfusions: technical advancement to improve outcomes in extracorporeal membrane oxygenation. J Thorac Dis 2018;10:5813-21.

4. Brierley J, Carcillo JA, Choong K, et al. Clinical practice parameters for hemodynamic support of pediatric and neonatal septic shock: 2007 update from the American College of Critical Care Medicine. Crit Care Med 2009;37:666-88.

5. Dellinger RP, Levy MM, Rhodes A, et al. Surviving sepsis campaign: international guidelines for management of severe sepsis and septic shock: 2012. Crit Care Med 2013;41:580-637.

6. Riera J, Argudo E, Ruiz-Rodríguez JC, et al. Extracorporeal membrane oxygenation for adults with refractory septic shock. ASAIO J 2018. [Epub ahead of print].

7. Huang CT, Tsai YJ, Tsai PR, et al. Extracorporeal membrane oxygenation resuscitation in adult patients with refractory septic shock. J Thorac Cardiovasc Surg 2013;146:1041-6.

8. Park TK, Yang JH, Jeon K, et al. Extracorporeal membrane oxygenation for refractory septic shock in adults. Eur J Cardiothorac Surg 2015;47:e68-74.

9. Extracorporeal Life Support Organization (ELSO): guidelines. Available online: https://www. elso.org/ Resources/Guidelines.aspx

10. Dellinger RP, Levy MM, Rhodes A, et al. Surviving sepsis campaign: international guidelines for management of severe sepsis and septic shock, 2012. Intensive Care Med 2013;39:165-228.

11. Napolitano LM. Sepsis 2018: definitions and guideline changes. Surg Infect (Larchmt) 2018;19:117-25.

12. Friesecke S, Stecher SS, Gross S, et al. Extracorporeal cytokine elimination as rescue therapy in refractory septic shock: a prospective single-center study. J Artif Organs 2017;20:252-9.

13. Xia W, Xu H, Mao W, et al. Extracorporeal membrane oxygenation as a bridge to lung transplantation. Zhonghua Wei Zhong Bing Ji Jiu Yi Xue 2018;30:1167-72.

14. Zhang YH, Guo GH, Shen GL, et al. Analysis on treatment of extremely severe burn patients with severe inhalation injury in August 2nd Kunshan factory aluminum dust explosion accident. Zhonghua Shao Shang Za Zhi 2018;34:455-8.

15. Nemeth E, Szigeti S, Varga T, et al. Continuous cytokine haemoadsorption incorporated into a venoarterial ECMO circuit for the management of postcardiotomy cardiogenic and septic shock-a case report. Perfusion 2018;33:593-6.

16. Choi MJ, Ha SO, Kim HS, et al. The simplified acute physiology score II as a predictor of mortality in patients who underwent extracorporeal membrane oxygenation for septic shock. Ann Thorac Surg 2017;103:1246-53.

17. Ro SK, Kim WK, Lim JY, et al. Extracorporeal life support for adults with refractory septic shock. J Thorac Cardiovasc Surg 2018;156:1104-9.e1.

18. Chang TH, Wu ET, Lu CY, et al. Pathogens and outcomes in pediatric septic shock patients supported by extracorporeal membrane oxygenation. J Microbiol Immunol Infect 2018;51:385-91.

19. Ferreira FL, Bota DP, Bross A, et al. Serial evaluation of the SOFA score to predict outcome in critically ill patients. JAMA 2001;286:1754-8.

20. Pope JV, Jones AE, Gaieski DF, et al. Multicenter study of central venous oxygen saturation $(\mathrm{ScvO} 2)$ as a predictor of mortality in patients with sepsis. Ann Emerg Med 2010;55:40-6.e1. 
21. Perz S, Uhlig T, Kohl M, et al. Low and "supranormal" central venous oxygen saturation and markers of tissue hypoxia in cardiac surgery patients: a prospective observational study. Intensive Care Med 2011;37:52-9.

22. Park JS, Kim SJ, Lee SW, et al. Initial low oxygen extraction ratio is related to severe organ dysfunction and high in-hospital mortality in severe sepsis and septic shock patients. J Emerg Med 2015;49:261-7.

23. Lee YK, Hwang SY, Shin TG, et al. Prognostic value of lactate and central venous oxygen saturation after early resuscitation in sepsis patients. PLoS One 2016;11:e0153305.

24. Shin TG, Jo IJ, Hwang SY, et al. Comprehensive

Cite this article as: Han L, Zhang Y, Zhang Y, Wu W, He P. Risk factors for refractory septic shock treated with VA ECMO. Ann Transl Med 2019;7(18):476. doi: 10.21037/atm.2019.08.07 interpretation of central venous oxygen saturation and blood lactate levels during resuscitation of patients with severe sepsis and septic shock in the emergency department. Shock 2016;45:4-9.

25. Boulain T, Garot D, Vignon P, et al. Prevalence of low central venous oxygen saturation in the first hours of intensive care unit admission and associated mortality in septic shock patients: a prospective multicentre study. Crit Care 2014;18:609.

26. Yeh YC, Lee CT, Wang CH, et al. Investigation of microcirculation in patients with venoarterial extracorporeal membrane oxygenation life support. Crit Care 2018;22:200. 